\title{
ESQUISTOSSOMOSE AGUDA AUTÓCTONE DE FOCO NA CIDADE DO RIO DE JANEIRO. ESTUDO DE 22 CASOS *
}

\author{
J. Rodrigues Coura, Leá Camillo-Coura, Alexandre Kalache e Carlos Alberto Argendo
}

Os autores descrevem a ocorrência de um veräadeiro "surto" da forma aguda da esquistossomose mansoni em um foco cujas características da espécie vetora, seus indices de infecção, a natureza e o local da exposição nada faziam supor esta possibilidade.

Foram estuaados 22 pacientes (14 crianças e 8 adultos) com a forma aguda da esquistossomose contraida em banho nas Furnas da Tijuca, no Rio de Janeiro, no periodo ae 9 a 22 de março de 1970. Todos os pacientes eram de côr branca $e$ de bom nivel social e foram infectados em banho único, ocasional, durante piquenique nesse logradouro.

As manitestaçoes clinicas foram severas em 7 casos, mcderados em outros 7 e discretos $\mathrm{cm}$ 8, caracierizando-se por febre em 17 sasos, hepatomegalia om 14. tosse sèca em 13, astenia em 13, diarréia em 12, emagrecimento em $11 \mathrm{ca}$ sos, colicas abdominais em 9, espienomegalia em 9, ch faleia em 7 casos e nauseas e vomitos $\mathrm{em}$ 3. O hemograma mosirou leucocitose e eosinofilia na grande mazoria aos casos e na eletroforese das proteinas séricas houve uma baixa da aloumma, aumento das giobulinas alja 2 e gama em alguns cusos. As bahsaminases estaiam no mars em todos. O periodo do incaioacio medio jor de 5 semanas.

Apos fazerem uma revisão sumária dos focou de esquistossomose no Estado da Guanabará, estudam a dinamica da transmissao nesie joeo recence anmi-

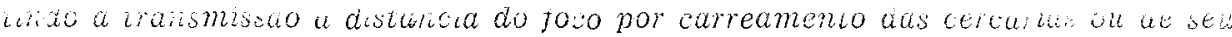
hospedeiro intermediario pela cigua.

A forma aguda ou toxêmica da esquistossomose mansoni é tida como rara ou pelo menos pouco diagnosticada, mesmo nas áreas de alta prevalência desta endemia $(13,15,17)$. Embora mais de uma centena de casos da forma toxêmica já tenha sido descrita por Neves e cols. (10. 11) $\mathrm{em}$ Belo Iorizonte e mais 25 outros casos assinalados por Ferreira \& cols, +3) na mesma cidade, o número de relatos desta forma clinica é extremamente reduzldo em outras áreas $17,12,14,18\}$, A infeccão azidental de pessoás ou famílias residentes nas grandes cidades quando em viagens, passeios ou férias em areas endêmicas de esquistossomose, como os casos descritos por Ferreira \& cols. (4), Macedo (6) e Coura \& cols. (1), parese contribuir com um importante contingente dos casos da forma toxérnica da doença. 
O objetivo dêste trabalho é o estudo de 22 casos de esquistossomose aguda em pacientes infectados na cidade do Rio de $\mathrm{Ja}-$ neiro, onde a doença tem ocorrido em focos isolados, circunsaritos e raros (hortas de agrião) transmitida pelo Biomphalaria tenagophila e apresentando-se até então com caráter de grande benignidade (portadores sãos ou pacientes oligossintomáticos). Os autores chamam a atenção para a ocorrência de um verdadeiro "surto" da forma aguda da doença em um foco cujas características da espécie vetora, seus indices de infecção, a natureza e local da exposição nada faziam supor esta possibilidade.

\section{MATERIAL E MÉTODOS}

Foram estudados 22 pacientes com a forma acuda da esquistossomose mansoni contraída em banho nas Furnas da Tijuca, no Rio de Janeiro, no período de 9 de fevereiro a 22 de março de 1970. Dos pacientes, 14 eram crianças e 8 adultos; 11 eram do sexo masculino e 11 do sexo feminino. Todos os pacientes eram de cô branca e de bom nivel social e foram infectados em banho único, ocasional, durante "piquenique" naquele logradouro.

Os pacientes nos foram encaminhados por colegas depois de fazerem várias hipóteses diagnósticas, entre as quais a mais frequiente foi a de febre tifóide. Todos foram submetidos à anamnese e exame clínico completo, hemograma, exame do sedimento urinário, coproscopia, raios-x do tórax e outros exames de rotina, como dosagem de glicose, uréia e creatinina no sangue e ainda a dosagem das proteínas séricas, "provas de função hepática", transaminases, fosfatase alcalina e eletroforese das proteínas séricas, na maioria dos casos.

Ao lado dos exames clínicos e laboratoriais dos pacientes, fêz-se uma investigação epidemiológica no local do banho suspeito e ainda uma minuciosa história dos pacientes e seus familiares sôbre viagens, passeios e banhos fora de casa nos últimos dois meses antes do início do quadro clínico atual, e da possibilidade de já haverem visitado focos endêmicos da esquistossomose anteriormente.

\section{RESULTADOS E COMENTÁRIOS}

Os resultados da investigação clínica e do leucograma dos 22 pacientes aqui estudados estão sumarizados nos quadros $I$ e II. Pôde-se verificar que 7 pacientes tiveram manifestaçoes clínicas severas, 7 outros apresentaran manifestecões de moderada intensidade e 8 tiveram manifestacōes discretas. O período de incubacão variou de 15 a 45 dias com uma média em tôrno de 5 semanas. A eosinofilia foi muito acentuada "pràticamente em todos os casos: apenas 3 casos apresentaram eosinofilia abaixo de $20 \%$. A leucometria global também mostrou-se elevada na maioria dos casos chegando até 21.650 por $\mathrm{mm}^{3}$ $\mathrm{em}$ um dêles; apenas 3 casos mostraram leucometria abaixo de 9.000 leucócitos por $\mathrm{mm}$. Em nenhum caso houve desvio do leucograma para a esquerda. Verificouse a presença de anemia em apenas 5 casos. cuja hemoglobina estava entre 9 e 12 gramas por $100 \mathrm{ml}$.

O exame de fezes realizado pelo método de Hoffman-Pons e Janner estava positivo em todos os casos ao fim do $2 .^{\circ}$ mês após o banho infectante.

Apesar de 13 pacientes apresentarem tosse sêca e persistente na fase aguda da doença, o raio-x do pulmão mostrou-se normal pràticamente em todos os casos. com exceção de um (caso n. ${ }^{\circ} 13$ ) que apresentou um nódulo apical calcificado, não relacionado com o quadro atual.

As chamadas provas de função hepática, turvação e floculação do timol, turvação do sulfato de zinco, cefalina colesterol e vermelho coloidal estavam normais ou discretamente alteradas. A dosagem da fosfatase alcalina em unidades Shinowara mostrou-se dentro dos limites da normalidade nos 14 casos em que foi realizada.

A transaminase glutâmica-pirúvica mostrou-se normal na maioria dos casos; apenas um caso teve uma discreta elevação (65 u F.) Aliás a normalidade das transaminases na fase aguda da esquistossomose mansoni já fôra comprovada em trabalho que realizamos em colaboração com Ferreira e outros (5) na infecção experimental do Cebus apella e por Mayrink \& Neves (8) em 15 pacientes desta forma clínica.

A eletroforese das proteínas séricas realizada em 15 pacientes (Quadro III) mos- 
ESTUDO DE 22 CASOS DA FORMA AGUDA DA ESQUISTOSSOMOSE MANSONI AUTÓCTONES DA CIDADE DO RIO DE JANEIRO(*)

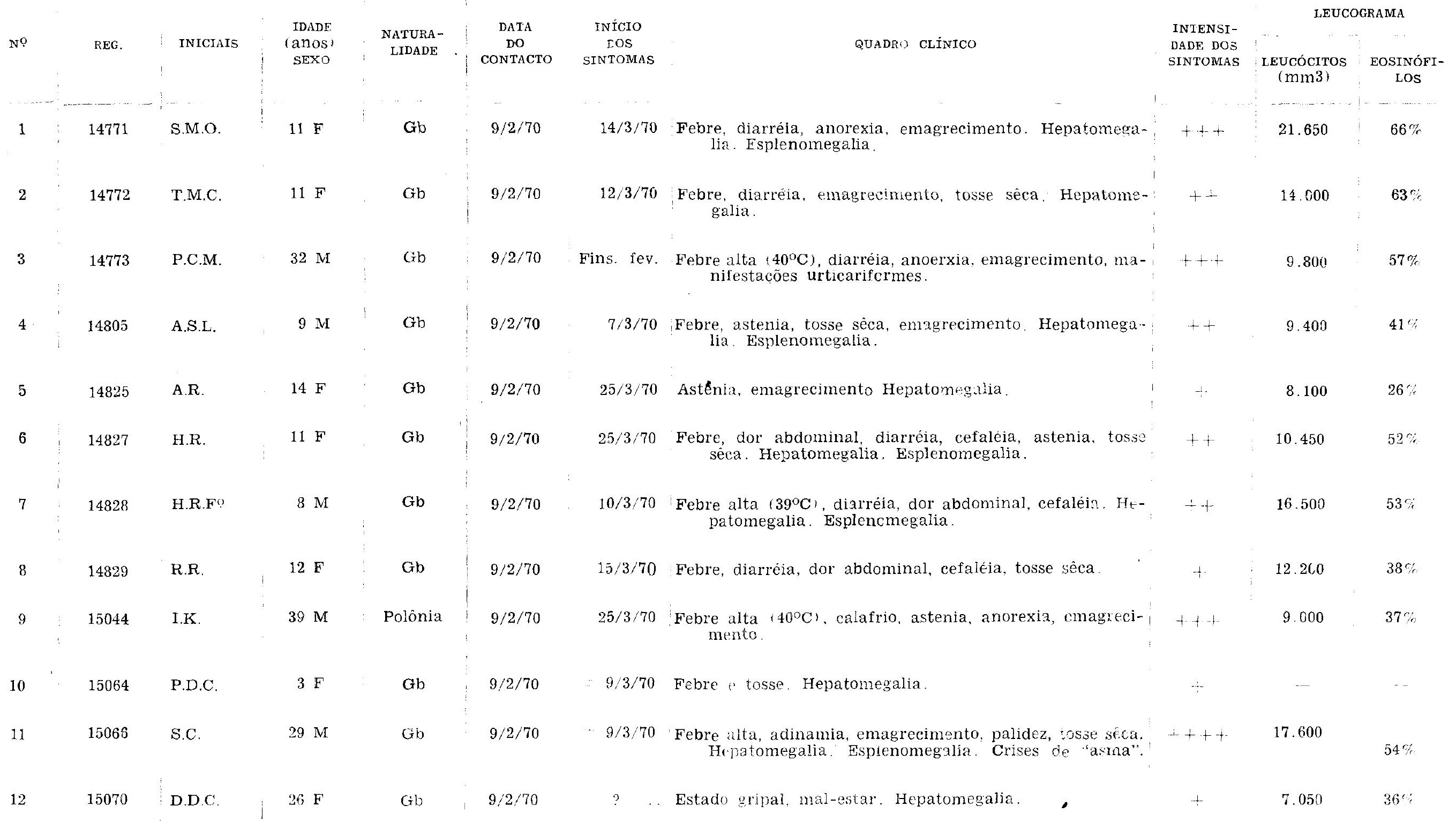


QUADRO I I Continuacão

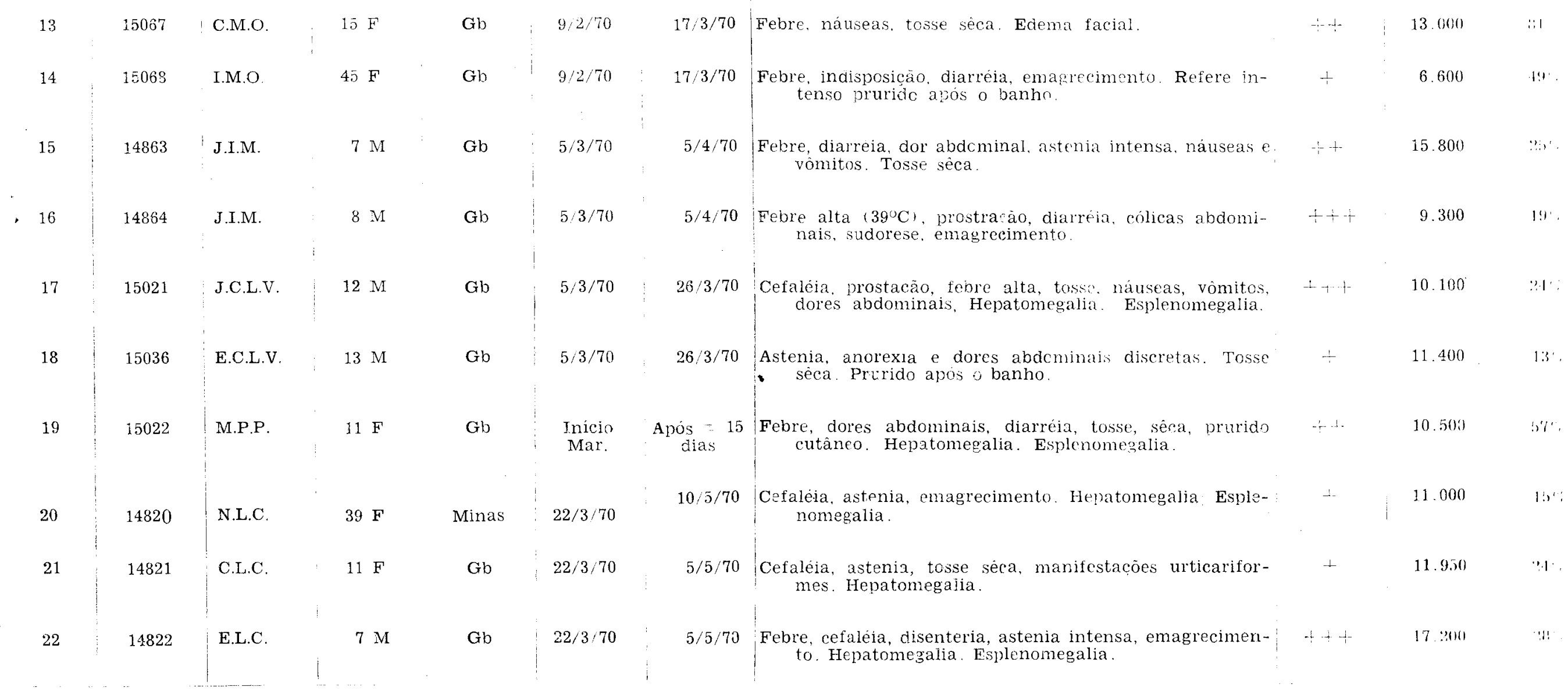

(*) Foco das Furnas da Tijuca Alto da Boa Vista). 
QUADRO II

QUADRO CLINICO EM 22 PACIENTES DA FORMA AGUDA DA ESQUISTOSSOMOSE MANSONI

\section{QUADRO CLINICO}

Nọ $\mathrm{DE}$ CASOS

Febre

Hepatomegalia

Tosse

Astenia

Diarréia

Emagrecimento

Cólicas abdominais

Esplenomegalia

Cefaléia

Náuseas e vòmitos

Urticária

Asma

Edema facial

trou elevação da fração a 2 isuperior a $0,8 \mathrm{~g} / 100 \mathrm{ml}$ em 9 casos, elevação da $\Upsilon$ globulina (superior a $1,8 \mathrm{~g} / 100 \mathrm{ml}$ ) em apenas 5 casos e baixa de albumina menos que
$3,5 \mathrm{~g} / 100 \mathrm{ml}$ ) em 12 casos. Os resultados da eletroforese das proteínas encontrados neste trabalho estão de acôrdo com os achados de Ribeiro \& col. (16) na fase aguda da esquistossomose mansoni.

Desde que Deane \& cols. (2) descreveram um foco ativo de esquistossomose mansoni em Jacarepaguá. no ex-Distrito Federal, atual Estado da Guanabara, confirmaram-se nesta área as previsões de Rodrigues da Silva (17), Alves Meira (9) e outros, que desde longa data chamavam a atenção das autoridades sanitárias para a iminente expansão da esquistossomose no sentido das correntes migratórias do Nordeste e região Centro-leste para o sul do país. Diversos focos da doença foram então assinalados no Paraná, São Paulo, Rio de Janeiro e Guanabara; nos dois últimos Estados destacavam-se os focos de Jacarepaguá, Duas Barras, Sumidouro, Niterói e São Gonçalo, cuja importância maior era, além de representarem a expansão da doença no sentido Nordeste-LesteSul, a de estarem localizados nas proximidades da grande metrópole do Rio de Janeiro. Entretanto, as formas clinicas assinaladas eram de extrema benignidade como já referimos na introdução dêste trabalho, não trazendo, portanto, maiores

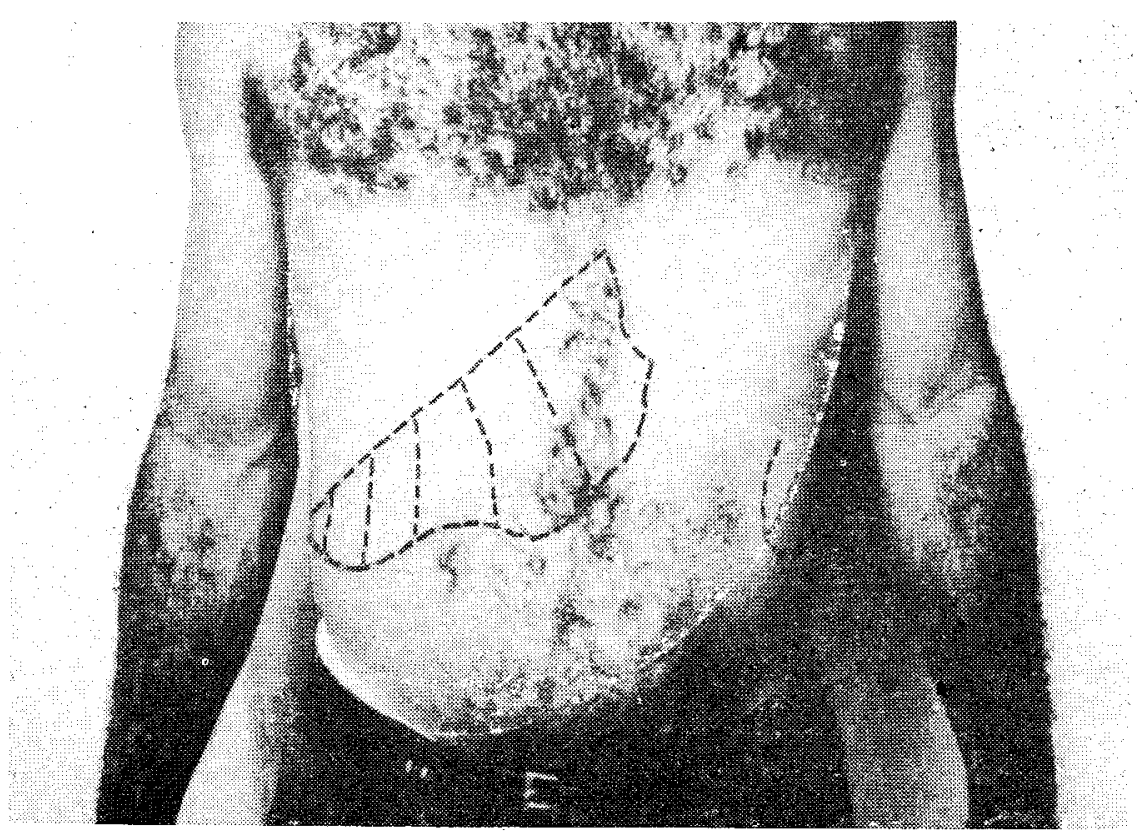

Fig. 1 - Paciente com a forma aguda da esquistossomose (caso n' 11) apresentando manifestaçōes clinicas severas. 
tância do foco, certamente pelo carreamento das cercárias ou de seu hospedeiro intermediário. Entretanto, no caso particular dêste foco torna-se difícil explizar a grande concentração de cercárias no volume da água existente, suficiente para produzir um quadro agudo, toxêmico, como nos casos aqui apresentados. Como nenhum dos pacientes estudados teve qualquer outro contato suspeito fora da área mencionada, temos de admitir como certo êste mecanismo de transmissão. Um minucioso estudo epidemiológico e da dinâmica de transmissão da doença nesta área deveria ser feito para explicar alguns fatos ainda obscuros na ocorrência dêste verdadeiro "surto" de esquistossomose aguda.

\section{SUMMARY}

An "outbreak" of 22 cases of acute schistosomiasis from o new fosus of $\mathrm{S}$. mansoni in the periphery of Rio de Janeiro City is described. Fourteen children and 8 adults were infected in a short pericd of time while bathing in a waterfall in whose vicinity no snails were found. A small distance away, and on a higher level, however, the Biomphalaria tenagofila was found but the number of snails infected with cercariae of $\mathrm{S}$. mansoni was very low. The authors believe that the explanation for this unusual "outbreak" could be that the snails or their cercariae had been washed down the waterfall in a recent heavy rainfall and thereby established the transmission of the disease.

Out of the 22 cases of acute schistosomiasis described in this paper, 7 had severe clinical manifestations, 7 had moderate symptoms and signs and 8 had a mild, acute form of the disease. Fever was present in 17 cases, hepatomegaly in 14, "dry cough" in 13, astenia in 13, diarrhea in 12, loss of weight in 11, abdominal pain in 9, splonomega!y in 9, headache in 7 and nausea and vomiting in 3. The white blood cells count and eosinophilia were very high in the majority of cases. The eletrophoresis of serum protein showed a low albumin rate and an elevation of $\alpha 2$ and $\gamma$ globuin in some cases. The liver function test, the transaminases, chest $X$-ray, urine, blood and other tests were normal. The incubation period had an average of five weeks (15 to 45 days).

\section{BIBLIOGRAFIA}

1). COURA, J. R., COUTINHO, S. G., MORAES, H. M., DIAS, L. B. RODRIGUES, N. P. \& RODRIGUES DA SILVA, J. - Esquistossomose pulmonar. O Hospital, 63: 993-1012, 1963.

2) DEANE, L. M., MARTINS, R. S. \& LÔBO, M. B. - Um foco ativo de esquistossomose mansônica em Jacarepaguá Distrito Federal. Rev. Bras. Mal. Doenc. Trop. 5; 549-552, 1953.

3) FERREIRA, H., OLIVEIRA, C. A., BITTENCOURT, D., KATZ, N., CARNEIRO, L. F. C., GRINBAUM. E., VELOSO, C., DIAS, R. P., ALVARENGA, R. J. \& DIAS, C. B.- A fase aguda da esquistossomose mansoni; consideraç̃es sôbre 25 casos observados em Belo Horizonte. J. Bras. Med., 11: 54$67,1966$.
4) FERREIRA, L. F. NAVEIRA, J. B. \& RODRIGUES DA SILVA, J. R. - Fase toxêmica da esquistossomose mansoni. Consideracões a propósito de alguns casos coletivamente cantaminados em uma piscina. Rev. Inst. Med. Trop. São Paulo, 2: 112-120, 1960.

5) FERREIRA, L. F., COURA, J. R., GAMA, M. P. \& TOSTA, C. E. - Equistossomose mansoni experimental, em Cebus apella. I. Determinação da transaminase glutâmico-pirúvica $\mathrm{e}$ glutâmico-oxalacética no sôro sanguíneo. Rev. Bras. Med. Trop. 1: 253$260,1967$.

6) MACEDO, A. G. - Esquistossomose aguda; diagnóstico de um caso na fase dita toxêmica. O Hospital, 59: $79-85,1961$. 
7) MARQUES, R. J. - A propósito da chamada fase toxêmica da esquistossomose mansônica. Anais Fac. Med. Univ, Recife, 17: 243-256, 1957.

8) MAYRINK, W. \& NEVES, J. - Anais Fac. Med. da Univ. Minas Gerais, 22: 195-198, 1967.

9) MEIRA, J.. A. - Esquistossomose mansoni. Subsídio ao estudo de sua incidência e distribuição geográfica no Brasil. Arq. Fac. Hig. Saúde Pública Univ. São Paulo. 1: 5-146, 1947.

10) NEVES, J., MARTINS, N. R. L., \& TONELLI, E. - Forma toxêmica da esquistossome mansoni; considerações diagnósticas em tôrno de 50 casos identificados em Belo Horizonte. O Hospital, 70 (6) : 1583-603, 1966. Anais Fac. Med. Univ. Minas Gerais, 22: 7598,1967 .

11) NEVES, J., SOUZA, D. W. C., ARAÜJO, P. K. A. \& MARINHO, R. P. Forma toxêmica da esquistossomose mansônica; registro de mais $70 \mathrm{ca}-$ sos identificados no Hospital Carlos Chagas da Faculdade de Medicina da Universidade Federal de Minas Gerais. Trabalho inscrito para apresentação no VII Congresso da Sociedade Brasileira de Medicina Tropical.

12) OLIVEIRA, J. L. - O periodo toxêmico da esquistossomose. Rev. Soc. Bras. Med. Trop., 3: 143-164, 1969.
13) PRATA, A. - In Veronesi Doenças Infecciosas e Parasitárias, 4. ${ }^{\text {a }}$ Edição, Editora Guanabara, Rio de Janeiro, 1969 .

14) PEREIRA, A. \& SIMON, R. - Sindrome eosinófilo febril neotropical. Arq. Soc. Med. Alagoas, 10: 11-45, 1954.

15) PESSOA, S. B. - Parasitologia Médica, 7. a Edição, Editora Guanabara, Rio de Janeiro, 1967.

16) RIBEIRO, L. P.. FERREIRA, L. F. \& RODRIGUES DÄ SILVA, J. - Eletroforese em papel das proteinas séricas na fase aguda da esquistossomose mansoni. O Hospital, 58: 233-240, 1960 .

17) RODRIGUES DA SILVA, J. - Estudo clínico da Esquistossomose mansoni. Tese, 452 págs. Fac. Med. Univ. Rio de Janeiro, 1949.

18) SERRAVALE, A. - Urticária febril esquistossomótica. Arq. Univ. Bahia, Fac. Med. 8: 169-175, 1952

19) SUASSUNA, A. \& COURA, J.R. Esquistossomose mansoni no Estado da Guanabara. Aspectos epidemiológicos relacionados às migrações internas. Rev. Soc. Bras. Med. Trop. 3: 59-71, 1969 . 